\title{
O papel do Médico de Família no diagnóstico e seguimento dos doentes com declínio cognitivo e demência
}

Rui Pereira Alves,* Ana Isabel Caetano**

\section{RESUMO}

Com o crescimento da população idosa assiste-se a um aumento da prevalência de patologias comuns neste grupo, em especial a demência.

Estima-se que a prevalência da demência na população da Europa Ocidental acima dos 60 anos seja 7,2\%.

A entrevista clínica ao doente, familiares e cuidadores visa a procura de alterações cognitivas e suas consequências no dia-a-dia do doente, assim como a pesquisa de sintomas que orientem para determinada etiologia da doença. Na entrevista clínica podemos utilizar testes pré-definidos como o Mini Mental State Examination que avalia o estado mental do doente, e o questionário sobre actividades funcionais para avaliar as repercussões funcionais na vida do doente.

O pedido de exames auxiliares de diagnóstico deve ser criterioso e orientado pela entrevista clínica e exame objectivo.

A referenciação para os cuidados secundários de saúde é importante para se estabelecer o diagnóstico e planear a terapêutica. Deve ser mantida uma boa comunicação entre os vários intervenientes, de forma a podermos acompanhar e gerir o plano terapêutico. Deve ser dada especial atenção aos familiares e cuidadores destes doentes, uma vez que estes apresentam um risco aumentado de determinadas patologias, como a depressão.

Um correcto e rápido diagnóstico das causas de demência, uma atempada referenciação e uma abordagem pluridisciplinar, focada no próprio, na doença e na família, permitem uma melhor gestão do doente com demência.

Palavras-chave: Demência; Cuidados Primários; Cuidadores; Tratamento.

\section{INTRODUÇÃO}

A demência é um problema de saúde com prevalência crescente na consulta de medicina geral e familiar e que atinge sobretudo a população mais idosa. Estima-se que, em 2010, a prevalência da demência, na Europa Ocidental, seja de $7,2 \%$, na população acima dos 60 anos. ${ }^{1}$ As alterações de memória e a demência são um motivo ou problema de saúde registado frequentemente na consulta de medicina geral e familiar, ocupando no capítulo P (Psicológico) da ICPC- $2^{2}$ uma posição de frequência imediatamente a seguir aos estados ansiosos e perturbações depressivas, abuso de substâncias (álcool, tabaco e drogas) e perturbações do sono.

*Médico de Família, Centro de Saúde de Sete Rios

**Médica Interna de Medicina Geral e Familiar, Centro de Saúde de Sete Rios
O doente demente apresenta alterações cognitivas progressivas, perturbações de memória, desorientação e confusão que condicionam um empobrecimento dos recursos e faculdades mentais, incapacidade na tomada de decisões e dificuldades nas actividades de vida diária. Os critérios de diagnóstico de demência são definidos pelo DSM-IV ${ }^{3}$ como «desenvolvimento de múltiplos défices cognitivos, incluindo comprometimento da memória, e pelo menos uma das seguintes perturbações cognitivas: afasia, apraxia, agnosia ou uma perturbação da função executiva, com repercussão a nível do funcionamento social ou profissional do doente, e representando um declínio em relação ao nível prévio».

\section{CAUSAS DE DEMÊNCIA}

$\mathrm{Na}$ abordagem do doente com suspeita de demência 


\section{QUADRO I. Causas de demência}

\section{DEMÊNCIAS PRIMÁRIAS - DEGENERATIVAS}

- Doença de Alzheimer

- Demência com Corpos de Lewy

- Degenerescência Lobar Frontotemporal

- Doença de Parkinson

- Doença de Huntington

- Paralisa supranuclear progressiva

- Degenerescência corticobasal

\section{DEMÊNCIAS SECUNDÁRIAS}

- Doenças vasculares cerebrais

- Traumatismos cranianos

- Tumores cerebrais

- Hidrocefalia de pressão normal

- Infecciosas: Neurosífilis; HIV; Meningite; Encefalite, D. Creutzfeldt-Jakob; Tuberculose

- Doenças desmielinizantes

- Metabólicas: Insuficiência Hepática e Renal; D. Wilson

- Endócrinas: Hiper/Hipotiroidismo; Hiper/Hipoparatiroidismo

- Doenças carenciais: Anemia Perniciosa, Défice de folatos

- Tóxicas: Álcool; Metais pesados; Corantes

- Medicamentosa: Antipsicóticos; Opiáceos; Anticolinérgicos; Anti-hipertensores; Anti-epilépticos

- Psiquiátricas: Depressão; Esquizofrenia

importa ter presente as possíveis causas. A demência como síndrome tem múltiplas causas, umas conhecidas - demências secundárias, e outras desconhecidas - demências primárias (Quadro I). ${ }^{4}$

A demência afecta sobretudo pessoas mais idosas, sendo a doença de Alzheimer a situação mais frequente, seguida das demências de causa vascular, da demência frontotemporal e da demência com corpos de Lewy. As restantes causas de demência são menos frequentes. ${ }^{5}$ As demências secundárias podem ser reversíveis, sendo necessário fazer um correcto e rápido diagnóstico, contando com o apoio fundamental dos cuidados secundários, designadamente a neurologia e a psiquiatria.

É importante salientar que, quanto à evolução, as demências podem ser potencialmente reversíveis, como nas intoxicações medicamentosas, nas secundárias a depressão ou a hidrocefalia de pressão normal, estáveis, como na demência secundária a traumatismo craniano, ou progressivas, como na doença de Alzheimer e restantes demências degenerativas. ${ }^{6}$

\section{QUADRO II. Aspectos a pesquisar na entrevista clínica}

\section{ANAMNESE - DOENTE E CUIDADORES}

- Alterações Cognitivas: Alterações da memória; dificuldade na comunicação escrita e falada; dificuldade em encontrar as palavras correctas, não reconhecimento de acontecimentos comuns e desorientação

- Sintomas Psiquiátricos: Depressão; ansiedade; insónia; apatia; alucinações; desconfiança/paranóia e consequente isolamento social

- Problemas Comportamentais: delírio; agitação; insónia ou inquietação nocturna

- Alterações Personalidade: afectos inapropriados; embotamento ou desinteresse; discursos agressivos/ /explosivos; sexualidade exagerada

- Alterações Funcionais: dificuldade nas actividades de vida diária (no trabalho, na condução, no uso de dinheiro); descuido pessoal/doméstico; desorientação espacial/temporal

- Antecedentes Pessoais: Hábitos medicamentosos e tóxicos; traumatismos; infecções

- História Familiar: Outros casos de demência precoce

\section{CLÍNICA DA DEMÊNCIA}

A história clínica tem um papel determinante no diagnóstico da demência. A entrevista clínica ao doente, aos familiares e ao cuidador é uma peça fundamental na colheita de informação. Interessa ser rigoroso e exaustivo focando os aspectos salientados no Quadro II.?

O modo de instalação da doença é também importante, uma vez que um quadro de instalação insidiosa, progredindo lentamente, pode apontar para uma doença degenerativa. ${ }^{8}$ Numa primeira fase, só os doentes notam as suas falhas. ${ }^{5}$ Sentem que a memória não corresponde como antes, que se esquecem de dados do dia-a-dia e que não dominam os assuntos, sendo estas dificuldades tanto mais evidentes quanto mais diferenciada ou intelectual for a actividade do doente. Os erros e as dificuldades vão-se agravando, tornando-se manifestos, e as falhas de memória acentuam-se. Os familiares ficam apreensivos, os doentes fazem disparates flagrantes, desorientam-se e podem perder-se. A personalidade deteriora-se, deixam de reconhecer os familiares e amigos e de identificar ambientes, e o discurso torna-se mais pobre. Apresentam dificuldade em vestir-se de modo adequado, perdem os modos à mesa 
e acidentalmente têm incontinência. Os doentes inquietos manifestam uma hiperactividade sem finalidade, necessitando de ser contidos. Por vezes têm alucinações e ideias paranóides e chegam a ser agressivos. Numa fase final ficam confinados à cama.

O exame físico geral é obrigatório. A presença de um sopro na auscultação das carótidas, a presença de sopros cardíacos e de alterações do ritmo podem sugerir uma causa vascular para a demência. Um aumento da tiroideia pode significar um hipo ou hipertiroidismo e uma demência secundária endócrina. A procura de sinais de hepatopatia, alcoolismo e insuficiência renal são obrigatórios. É também importante avaliar as acuidades visual e auditiva, que, se seriamente comprometidas, dificultam o relacionamento do doente com o ambiente, podendo dar a impressão de declínio cognitivo.

O exame neurológico sumário é importante. A presença de sinais neurológicos focais, sinais parkinsónicos, alteração dos movimentos oculares, atrofias musculares, ou sinais meníngeos, entre outros, pode apontar para a etiologia da demência. Os doentes sem sinais neurológicos, ou com sinais neurológicos discretos, poderão ter uma demência degenerativa, uma doença psiquiátrica como a depressão ou uma doença metabólica.

A avaliação do estado mental assenta na entrevista com o doente e familiares e no resultado de testes rápidos como o Mini Mental State Examination (MMSE) ${ }^{9}$ que avalia a orientação, atenção, retenção, linguagem e habilidade para cumprir ordens. Este é o teste de rastreio cognitivo mais utilizado, e de rápida execução, sendo a interpretação da pontuação obtida feita de acordo com a idade e escolaridade do doente. Considera-se défice cognitivo uma pontuação $\leq 15$ para analfabetos, $\leq 22$ para escolaridade entre 1 e 11 anos $\mathrm{e} \leq 27$ para escolaridade superior.

A avaliação do estado funcional documenta as capacidades funcionais do doente e é avaliada pela informação obtida através do doente, família e cuidador, podendo ser utilizado um questionário rápido - Questionário sobre Actividades Funcionais (Quadro III). ${ }^{10} \mathrm{~A}$ resposta a cada item é pontuada numa escala de 0 a 3 , sendo que: normal $=0$; sozinho mas com dificuldade = 1 ; requer ajuda $=2$; dependente $=3$. O Grupo de Estudos de Envelhecimento Cerebral e Demências tem um conjunto de escalas e testes, aferidos para a população portuguesa, que devem ser utilizados na avaliação do
QUADRO III. Questionário sobre actividades funcionais (FAQ)

- Assuntos de natureza financeira, pagamento de contas, preenchimento de cheques

- Declaração de impostos, assuntos económicos

- Compras do dia-a-dia

- Hobbies ou jogos

- Fazer um chá, pôr e tirar a cafeteira do lume

- Cozinhar uma refeição equilibrada

- Percepção de acontecimentos actuais

- Nível de atenção e compreensão: livros e televisão

- Memória: recordar encontros e horas de tomar medicamentos

- Passear: conduzir o próprio carro ou apanhar os transportes públicos

doente com suspeita de demência e aplicados por psicólogos treinados.

\section{DIAGNÓSTICO DIFERENCIAL}

Estabelecendo-se o diagnóstico de demência, interessa determinar a natureza da doença e identificar as causas potencialmente reversíveis, recorrendo, se necessário, a exames auxiliares de diagnóstico (Quadro IV). O exame neuropsicológico por psicólogo competente e a referenciação para neurologia e/ou psiquiatria são recursos que podem ser usados e contactos que devem ser mantidos no acompanhamento dos doentes com demência.

Na clínica da demência dos idosos há algumas situações de diagnóstico diferencial difícil: entre demência incipiente e normalidade, entre demência e depressão e entre doença de Alzheimer e demência frontotemporal. ${ }^{5}$ No diagnóstico diferencial entre demência incipiente e normalidade ter-se-á que reconhecer que, muitas vezes, a passagem do tempo esclarecerá o diagnóstico. Muitas pessoas idosas apresentam queixas de dificuldade de memória sem que cheguem a apresentar um quadro de demência, podendo tratar-se de um defeito cognitivo ligeiro. Consideram-se critérios de diagnóstico desta entidade: queixas de dificuldades nemésicas, de preferência confirmadas por um acompanhante, defeito de memória tendo em conta a idade e escolaridade, função cognitiva geral preservada, activi- 
QUADRO IV. Exames auxiliares de diagnóstico a pedir

EXAMES AUXILIARES DE DIAGNÓSTICO

- Laboratorial: Hemograma; Glicémia; Vitamina B12 e Ácido Fólico; lonograma; Cálcio; Função hepática, renal e tiroideia; Tiamina sérica; VDRL; TPHA; HIV; VS; Urina II; Pesquisa de tóxicos/drogas/metais pesados

- Radiológico: TAC-CE; Rx Tórax, ECG

dades do dia-a-dia intactas e ausência de demência. ${ }^{4}$ Os doentes com defeito cognitivo ligeiro devem de ser tratados e seguidos clinicamente.

A depressão é um sintoma frequente na demência, por vezes difícil de reconhecer. As mudanças no comportamento como novos hábitos ou perda dos adquiridos, agitação, irritabilidade, comportamentos apelativos ou dependentes, insónia, sentimentos de culpa, pensamentos de morte ou suicídio, são mais frequentes no doente deprimido com demência. ${ }^{6} \mathrm{O}$ idoso deprimido pode manifestar tristeza persistente, anedonia, perturbações do sono e apetite, fadiga fácil, lentificação psicomotora, ideias de ruína e pensamentos recorrentes sobre a morte. ${ }^{8}$

\section{O DOENTE, A FAMÍLIA E O MÉDICO DE FAMÍLIA}

Todos os doentes dementes têm algum grau de dependência. No caso dos doentes com Alzheimer, logo muito cedo começam a necessitar de vigilância e apoio. ${ }^{8}$

A doença de Alzheimer representa um enorme fardo para as famílias dos doentes, quer no aspecto económico, quer no aspecto emocional e físico. ${ }^{11} \mathrm{O}$ médico de família, para ser eficaz, tem que estar disponível, interessado e disposto a dialogar com a família. Deve programar consultas cada 4 a 6 meses, na unidade de saúde, com o doente acompanhado ou no domicílio. ${ }^{11}$ Nestas consultas deve ser avaliada a progressão da doença e intercorrências, estado de nutrição e de higiene, eventuais ambientes de risco presentes no domicílio e deve ser sempre vigiada a medicação e efeitos colaterais da mesma. ${ }^{11}$

Os cuidadores dos doentes com demência são muitas vezes da mesma idade ou mais velhos apresentando também vulnerabilidades a que é preciso atender. É frequente o cansaço e a exaustão dos cuidadores, resultante da maior pressão e responsabilidade, ${ }^{11}$ pelo que estes necessitam de uma palavra de ânimo e de encorajamento e um esforço de diálogo para rever a programação de cuidados.

Os filhos dos doentes com demência manifestam, por vezes, grande ansiedade e medo de contrair a doença, sendo fundamental fornecer informação correcta à luz dos conhecimentos actuais. A este propósito, convém referir que a causa de doença de Alzheimer é desconhecida, excepto em raros casos familiares de início precoce, antes dos 60 anos, em que a doença pode ser causada por mutações em 1 de 3 genes: presenilina 1 , presenilina 2 e proteína precursora do $\beta$-amilóide (APP). ${ }^{4}$

O médico de família, porque conhece a dinâmica familiar, encontra-se numa posição privilegiada para ajudar na gestão dos cuidados e até reconhecer as dificuldades em manter o doente no seu domicílio. O médico de família deve conhecer os recursos existentes na comunidade e que podem ser úteis para o doente como os centros de dia, os cuidados continuados no domicílio, as instituições com internamento, de forma a avaliar com a família o mais adequado para o doente. Deve também facultar à família contactos de instituições que podem informar e orientar sobre a demência de Alzheimer, como por exemplo a Associação Portuguesa de Familiares e Amigos de Doentes de Alzheimer (APFADA).

\section{TRATAMENTO}

Os objectivos do tratamento são tratar as causas de demência susceptíveis de serem corrigidas e providenciar conforto e suporte para o doente e cuidadores. ${ }^{8} \mathrm{O}$ tratamento deve ser instituído com o apoio e orientação dos cuidados de saúde secundários (neurologia e psiquiatria) e de acordo com os recursos existentes psicólogos, terapeutas ocupacionais, enfermeiros e assistentes sociais.

O doente com demência beneficia com terapêutica farmacológica específica: donepezil, galantamina, rivastigmina e memantina, que pode ser complementada com a terapêutica psicológica necessária para a reabilitação das funções cognitivas afectadas. ${ }^{4}$

As terapias comportamentais apresentam um papel importante. O objectivo é tornar a vida do doente confortável, simples e segura, permitindo-lhe tanta liberdade quanto possível, adaptando o ambiente com medidas simples que evitem acidentes e reduzam a confusão. 


\section{QUADRO V. Tratamento da demência}

\section{TRATAMENTO NÃO FARMACOLÓGICO}

- Psicológico (doente e família): Psicólogo clínico; terapeuta ocupacional

- Social: Promoção de segurança do domicílio, prevenção de quedas; prevenção de comportamentos de risco; cuidados domiciliários; prestação de serviços; exercício físico; «clube de encontros»; centro de dia

- Treino da memória: associações visuais e uso de lembretes

- Modificação do comportamento: reforçado positivo do comportamento desejado

- Orientação para a realidade

- Terapia da validação

- Terapia da reminiscência

- Clínicas de memória

FARMACOTERAPIA: Demência de Alzheimer

- Inibidores da Acetilcolinesterase: Donepezil; Galantamina; Rivastigmina

- Antagonista do N-metil-D-Aspartato: Memantina

FARMACOTERAPIA: Demência vascular

- Antihipertensores

- Estatinas

- Antiagregação plaquetar: AAS; Clopidogrel

- Anticoagulação: Varfarina; Heparinas

FARMACOTERAPIA: não cognitiva

- Antidepressivos; Antipsicóticos atípicos

Ao estruturar as tarefas domésticas, é necessário familiarizar o doente com os objectos e com a casa, estabelecer um horário para refeições, medicação e deitar. Devem-se programar rotinas e tarefas familiares, passeios e exercício físico simples e estimular actividades lúdicas, como dançar ou jogar. ${ }^{11}$

Os doentes com demência têm tendência a opor-se ao facto de estarem a perder competências para conduzir, fazer compras, cozinhar e tratar das suas finanças. Podem reagir violentamente, com raiva e até mesmo deprimirem-se, caso a sua família tente ajudar. A resposta hostil dos cuidadores é inútil e por vezes dolorosa, pelo que afirmações calmas, explicações serenas, distracção e securização, são respostas mais produtivas neste cenário. ${ }^{12}$
A mudança de cuidador ou a adição de novos cuidadores no domicílio pode aumentar a confusão e agitação, pelo que a introdução de uma nova pessoa deve ser cuidadosa e acompanhada de mensagens amáveis e de segurança. ${ }^{11} \mathrm{~A}$ frequência de um centro de dia e o internamento num lar ou residência assistida deve ser programada, apelando aos benefícios, que virão para o bem-estar do próprio, oferecidos pelos técnicos e cuidados de atenção e vigilância permanente. ${ }^{8}$

O plano terapêutico a instituir deve ser da responsabilidade dos médicos intervenientes no tratamento (QuadroV). A medicação específica deve ser periodicamente revista assim como os seus efeitos secundários: anorexia, náuseas e vómitos, dispepsia, diarreia, cólicas abdominais, perda de peso, hipersudorese, síncope, bradirritmia, cãibras, insónia e agitação. Atenção especial deve ser dada aos doentes com patologia concomitante do aparelho digestivo, em que o risco de hemorragia digestiva é maior, patologia respiratória em que o risco de crise asmática é maior, e do sistema nervoso central que apresenta um risco acrescido de convulsões. O risco de queda, com consequente fractura, pode aumentar com algumas das medicações instituídas. ${ }^{4}$ Os medicamentos que afectam a cognição, se possível, devem ser descontinuados. As comorbilidades que o doente apresenta têm de ser tratadas, devendo apenas usar-se os medicamentos estritamente necessários e atender à titulação das doses.

A terapêutica da demência vascular tem como objectivo a prevenção secundária do acidente vascular cerebral. O controlo da tensão arterial, do nível de glicémia e colesterol, bem como a cessação tabágica, a diminuição do peso e o exercício físico, e se indicado a anti-agregação plaquetária, são objectivos fundamentais para a redução do risco cardivascular.,13

A deambulação é um problema sério e frequente que requer especial cuidado de avaliação. ${ }^{12} \mathrm{O}$ doente tem dor? Tem outro problema de saúde? Infecção urinária? Os métodos de restrição forçada dos movimentos devem ser o último recurso e sempre com o acordo da família. Deve-se evitar a medicação sedativa sem reconhecer a causa para esta agitação.

As medidas preventivas utilizadas neste grupo etário, nomeadamente a vacinação contra a gripe, pneumonia e tétano, estão indicadas nos doentes com doença crónica em que se incluem os doentes com demência. ${ }^{14}$ 
Atenção especial deve merecer a frustração e depressão dos familiares e cuidadores. A culpa e o esgotamento dos cuidadores são muito comuns. ${ }^{12}$ Os cuidadores e familiares sentem-se frequentemente esgotados e podem descarregar as suas frustrações nos doentes. Nesta situação a família deve ser encorajada a aproveitar os recursos disponíveis na comunidade que a possam aliviar. Já foi mencionado anteriormente o papel dos grupos de apoio organizados, como as associações de doentes. Nas fases mais adiantadas da demência, e tendo em atenção o estado do doente, deve ser discutido com os familiares os cuidados terminais e prever o internamento do doente em residências assistidas. Face à culpabilidade da família, esta deve ser ajudada a enfrentar a separação.

A gestão do tratamento dos doentes com demência e a repercussão que esta patologia crónica introduz na família é um desafio para o médico de família, exigindo ponderação, trabalho em equipa e grande disponibilidade.

\section{REFERÊNCIAS BIBLIOGRÁFICAS}

1. Prince M, Jackson J. World Alzheimer report 2009. Alzheimer s disease international. Disponível em: http://www.alz.co.uk/research/files/ World\%20Alzheimer\%20Report\%20Executive\%20Summary.pdf [acedido em 02/12/2009].

2. Wonca, Comissão Internacional de Classificações. ICPC-2: International Classification of Primary Care, 2nd edition. Geneva:WONCA; 1999.

3. American Psychiatric Association. Diagnostic and Statistical Manual of Mental Disorders. 4th ed. Whashigton, DC:American Phychiatric Association; 1994.
4. Ferro J, Pimentel J. Neurologia: princípios, diagnóstico e tratamento. Lisboa: Lidel; 2006.

5. Associação Portuguesa dos Médicos de Clínica Geral. MGF 2000: Manual de Medicina Geral e Familiar. Lisboa: APMCG; 2001.

6. Garcia C, Coelho MH. Neurologia Clínica: Princípios Fundamentais. Lisboa: Lidel; 2009.

7. Ribeira S, Ramos C, Sá L. Avaliação inicial da demência. Rev Port Clín Geral 2004 Set-Out; 20 (5): 569-77.

8. Kasper DL, Fauci AS, Longo DL, Braunwald E, Hauser SL, Jameson JL. Harrison Principles of Internal Medicine. 17th ed. NewYork: McGraw-Hill; 2008.

9. Folstein MF, Folstein SE, McHugh PR. Mini-mental state: a practical method for grading the cognitive state of patients for the clinician. J Phychiatr Res 1975 Nov; 12 (3): 189-98.

10. Pfeffer RI, Kurosaki TT, Harrah CH Jr, Chance JM, Filos S. Measurement of functional activities of older adults in the community. J Gerontol 1982 May; 37 (3): 323-9.

11. Taylor RB, David AK, Johnson TA, Philips DM, Scherger JE. Family Medicine: Principles and Practice. 6th ed. New York, NY: Springer; 2003.

12. Rakel E. Tratado de medicina da família. $5^{\text {a }}$ ed. 1997.

13. Roger J, Britten N, Culpepper L, Gass D, Grol R, Mant D, Silagy C, editors. Oxford Textbook of Primary Medical Care 2005. New York, NY: Oxford University Press; 2005.

14. Direcção-Geral da Saúde, Divisão de Doenças Transmissíveis. Programa Nacional de Vacinação 2006 - Orientações Técnicas $10^{\text {a }}$ ed rev. Lisboa: DGS; 2005.

Os autores declararam não possuir conflitos de interesse.

\section{ENDEREÇO PARA CORRESPONDÊNCIA}

Ana Isabel de Oliveira Caetano

Rua Engenheiro Ferreira Dias, Lt $109-4^{\circ} \mathrm{A}$

1950-116 Lisboa

Email: anakaetanomgf@gmail.com

\section{ABSTRACT}

\section{THE ROLE OF THE FAMILY PHYSICIAN IN THE DIAGNOSIS AND MONITORING OF PATIENTS WITH COGNITIVE DECLINE AND DEMENTIA}

The aging of the population is a fact in our society. In conjunction with this process an increased prevalence of diseases common in the elderly, especially dementia, is found.

The interview of the patient, family and caregivers aims to search for cognitive changes and their impact on day-to-day, as well as a research to specific etiologies. In the interview the use of clinical tests to assess the mental state of the patient and the functional consequences in their activities is mandatory.

The application of diagnostic tests, as well as referral to secondary care providers should be judicious and timely so that the correct therapeutic approach can be provided.

A good communication between the various stakeholders, must be kept, so that we can monitor and manage the treatment plan. A special attention to the families and caregivers is necessary, since they have a higher risk of diseases such as depression.

Keywords: Dementia; Primary Care; Caregivers; Treatment. 